\title{
Adhesion of Human Neuroblasts to HIV-1 tat
}

\author{
P. CORNAGLIA-FERRARIS, A. DE MARIA, C. CIRILLO, A. CARA, AND G. ALESSANDRI \\ Department of Pediatric Hematology/Oncology, G. Gaslini Childrens' Hospital, Genoa, Italy \\ [P.C.-F., G.A.], University of Genoa Medical School, Department of Infectious Disease, Genoa, Italy \\ [A.D.M., C.C.], and Tumor Cell Biology Laboratory, NCI, NIH, Bethesda, Maryland
} \begin{abstract}
ABST
Several neuropathologic findings in infants and children with
human immunodeficiency virus type-1 (HIV-1) infection are different from those observed in adults, probably related to the fact that the retroviral infection occurs in the setting of neurodevelopment. This report describes the interaction and biologic activity of tat, the HIV-1 trans-activating protein on human neuroblasts. Two human neuroblastoma cell lines, LAN-5 and GI-CA-N, have been studied for their capability to adhere to tat (full recombinant protein) and to two different peptide residues of it. Both cells adhere to tat and tat ${ }^{46-60}$ basic domain, although not to $t a t^{65-80}$ residue, which contains the RGD (arginineglycine-aspartic acid) motif. Adhesion to collagen I was inhibited by preincubating GI-CA-N cells with $t a t,{ }^{46-60}$ although not with tat, ${ }^{65-80}$ indicating the capability of the basic residue to interfere with collagen I-induced cellular adhesion. The expression of $200-\mathrm{kD}$ neurofilaments induced by collagen I was not induced by tat ${ }^{46-60}$ indicating that neural differentiation along the same pathway is not mimicked by this peptide. Neuroblast cell proliferation was not affected by adhesion to $t a t^{46-60}$ nor to tat. ${ }^{65-80}$ GI-CA-N cells are not permissive to HIV-1 infection. However, proviral DNA was documented in the cell lysate for 14 consecutive in vitro passages, whereas HIV-1 transcription was never
\end{abstract}

HIV-1, the etiologic agent of AIDS, is often complicated with neurologic disorders (1). HIV-1-associated neurologic disease occurs as the initial presenting clinical manifestation of AIDS in $3-7 \%$ of infected patients, but in up to $18 \%$ of children (2). In infants infected with HIV-1, the CNS is involved earlier than in adults, partly related to the fact that the retroviral infection occurs in the setting of neurodevelopment (3). Intrinsic effects of HIV-1 on the infant's CNS include microcephaly, diffuse gliosis, and basal ganglia mineralization (3). In addition, an intrinsic HIV-1-induced damage has been indirectly demonstrated by the successful treatment of various forms of dementia and neurologic symptoms with zidovudine (4-6). Moreover, HIV-infected children have altered cortisol secretion, probably associated with specific CNS damage (7). The pathogenic mechanisms of neurologic dysfunction and

Received July 20, 1994; accepted May 25, 1995.

Correspondance and reprint request: Paolo Comaglia-Ferraris, M.D., G Gaslini Research Children's Hospital, 16148 Genova-Quarto, Italy. detectable. This would exclude the possibility that tat would be transduced by these cells. GI-CA-N stained negative for CD4, although positive for Gal-C, which may explain HIV-1 entry. Results show that immature human neural cells interact with tat protein and/or its basic residue in vitro. A mechanism similar to that herein described would possibly be active in vivo, which may help in clarifying the pathogenic mechanisms of neurologic dysfunction and destruction of the CNS observed in infants infected with HIV-1. (Pediatr Res 38: 792-796, 1995)

\section{Abbreviations}

HIV-1, human immunodeficiency virus type 1

ECM, extracellular matrix

TNF- $\alpha$, tumor necrosis factor- $\alpha$

$\gamma$-IFN, $\gamma$-interferon

TGF- $\boldsymbol{\beta} 1$, transforming growth factor- $\beta 1$

NB, human neuroblastoma

PCR, polymerase chain reaction

Coll, collagen

RT, reverse transcriptase

B-LCL, B lymphoblastoid cell line

VIP, vasoactive intestinal peptide destruction-whether a result of direct cellular infection of HIV, secondarily produced and up-regulated cytotoxic cytokines, or co-infection with opportunistic pathogens-remain an area of active research. During early human brain development, HIV-1 may influence the differentiation processes of CD4 ${ }^{-}$neuroblasts and oligodendrocyte precursors, resulting in dysmyelination and gliosis (1-7).

Neural cell adhesion to ECM protein is a crucial step in both neural cell differentiation and function $(8-16)$. We recently showed that agents affecting neuroblast differentiation, such as retinoic acid, TNF- $\alpha$, and $\gamma$-IFN, modulate NB cell differentiation; this includes integrin receptor expression (17) and induction of HLA class II antigen (18). Thus, changes in NB cell-adhesion properties are part of the maturational processes induced by the various differentiators $(13,14)$. In the nervous system integrins are the major class of adhesion receptors and mediate the differentiating effects of ECM components on neural cells during development (7-18). 
The HIV-1 trans-activator protein tat has been implicated as a mediator of neuronal dysfunction in several model systems (19-24). In a recent report, Kolson et al. (23) showed that tat induced a marked aggregation of neurons and astrocytes in primary rodent brain cell cultures and caused the neuritic processes to coalesce into fascicles, thus affecting neural cell adhesion processes. These effects mapped to a different region from the trans-activation domain of tat, as mutating the RGD sequence within the second exon abrogated aggregation and fascicle formation without affecting trans-activation capacity. PC12, a rat pheocromocytoma-derived cell line, would also be affected by tat in their differentiation/proliferation processes (19).

Proliferation and differentiation of human cells other than neural cells is affected by tat. By studying spindle-shaped cells of vascular origin, that are the probable tumor cells of Kaposi sarcoma, Barillari et al. (24) showed that tat promotes the adhesion of AIDS-Kaposi sarcoma as well as normal vascular cells. Such an adhesion is associated with the amino acid sequence RGD of tat through a specific interaction with the integrin receptors $\alpha 5 \beta 1$ and $\alpha(\mathrm{v}) \beta 3$, although it is augmented by the basic region, the $46-60$ domain. Moreover, the expression of both integrins is increased by cytokines promoting these cells to acquire spindle morphology and become responsive to the adhesion and growth effects of tat. Barillari's results strongly suggest that RGD-recognizing integrins mediate both adhesion and vascular cell growth-promoting effect of tat.

By studying the modulation of integrin receptors induced by $\gamma$-IFN in human NB cells, we previously showed a specific modulation of $\alpha 1 \beta 1, \alpha 2 \beta 1$, and $\alpha 3 \beta 1$ along with the neural differentiation process (15). In this report we analyze the adhesion, proliferation, and morphologic changes due to HIV-1 tat and discuss the possible implication of neural cell adhesion disturbance by tat in the etiology of CNS damage by HIV-1.

\section{METHODS}

Chemicals. Human ECM, including laminin, fibronectin, Coll I, Coll IV, and vitronectin were purchased from Sigma (St Louis, MO). tat-derived peptides were produced by Neosystem (Strasbourg, France); tat ${ }^{46-60}$ was synthesized according to the following sequence: S-Y-G-R-K-K-R-R-P-P-Q, whereas the tat $^{65-80}$ sequence was: H-Q-V-S-L-S-K-Q-P-T-S-Q-P-R-G-D. Poly-D-lysine was purchased from Polyscience Inc. (Warrington PA). FCS, BSA and cell culture media were all from Seromed. VIP and substance $P$ were both from Sigma.

Cell lines. LAN-5 NB cell line was a generous gift of $\mathrm{R}$. Seeger (UCLA), whereas the GI-CA-N cell line was established in our laboratory as described elsewhere (26).

Cell adhesion. Cell lines and methods have been previously described in detail $(15,16,26-29)$. Briefly, GI-CA-N and LAN-5 cells were harvested with PBS, resuspended in RPMI 1640, and seeded on 96-well plates (Costar, Cambridge MA) previously coated with ECM substrates or tat residues (10 $\mu \mathrm{g} / \mathrm{ml}$ final concentration on plastic plates preactivated with bis-bromo-sulfosuccynimidyl-suberate, BS3, Pierce). Poly-Dlysine was used as a control. Coating was performed overnight at $4^{\circ} \mathrm{C}$, then the plates were washed twice with PBS and incubated for $1 \mathrm{~h}$ at room temperature with $0.1 \%$ BSA in PBS. After two additional washes, cells were plated and incubated for $1 \mathrm{~h}$ at $37^{\circ} \mathrm{C}$. Unattached cells were washed out with PBS, whereas adherent cells were fixed and stained with cresyl violet in $20 \%$ methanol. After solubilization with $0.1 \mathrm{M}$ citric acid in $50 \%$ ethanol, $A_{600}$ was measured by microplate reader Metertech, model $\Sigma 960$. The percentage of cells attached to ECM, poly-D-lysine and tat peptides was calculated as described elsewhere (15).

To evaluate whether tat fragments were able to compete with ECM proteins, preincubation of both cell lines with tat-derived peptides was performed. Cells were preincubated for $1 \mathrm{~h}$ at $37^{\circ} \mathrm{C}$ with $\operatorname{tat}^{46-60}$ or to tat $^{65-80}$ at the concentration of $100 \mu \mathrm{g} / \mathrm{ml}$, washed, and tested in the adhesion assay. A preincubation with control peptides, including VIP and substance $\mathrm{P}$, was performed under the same conditions. To test whether Coll I receptor was involved in $t^{4 t^{46-60}}$ recognition, a preincubation with soluble Coll I was performed for $1 \mathrm{~h}$ at $37^{\circ} \mathrm{C}$. Cells were then washed and tested in the adhesion assay.

Integrin pattern. The expression of integrin receptors was evaluated by means of immunoprecipitation and/or RT-PCR as recently described in detail (15).

Cell proliferation and morphology. NB cells proliferation was evaluated by $\left[{ }^{3} \mathrm{H}\right] \mathrm{TdR}$ incorporation as described before in detail (23). Morphologic and immunophenotype changes were also evaluated by mean of immunocytochemistry as described elsewhere $(15,16,26-29)$. Briefly, the percent of positive cells was evaluated by two different researchers, blind to study senses. Data were expressed as the mean $\pm \mathrm{SD}$ of four different experiments (see Table 2 legend for further details).

Proliferation of NB cells was also tested on 96-well plates precoated with tat residues and control peptides, including substance $\mathrm{P}$ and BSA.

HIV-l infection. Infection with HIV-1 was obtained by co-cultiring GI-CA-N with a B-LCL chronically infected with HIV-1 $1_{\text {IIIB }}$, as described elsewhere (30). Briefly, B-LCL cells obtained by transformation of peripheral blood lymphocytes with EBV were acutely infected with $\mathrm{HIV}-1_{\text {IIIB }}(30)$. To this end, $1 \times 10^{6}$ B-LCL were incubated with $100 \mu$ l of stock HIV-1 $1_{\text {IIIB }}$ supernatant in a final volume of $1 \mathrm{ml}$ corresponding to a multiplicity of infection of approximately 0.01 . After incubation at $37^{\circ} \mathrm{C}$ for $32 \mathrm{~h}$, the cells were extensively washed and cultured in T50 cell culture flasks in RPMI 1640 (Life Technologies, Inc.) $+10 \%$ FCS (ICN-Flow).

The time course of infection was monitored by the determination of HIVp24 antigen appearance in supernatants. On d 7 postinfection, when virus replication reached approximately $50 \%$ of peak levels, the HIV-1-infected B-LCL were washed extensively and $\gamma$-irradiated (7000 rad). After further washing, $10^{5}$ B-LCL infected with HIV-1 $1_{\text {IIIB }}$ were co-cultured with $5 \times$ $10^{5}$ GI-CA-N cells that had been plated $24 \mathrm{~h}$ previously in duplicate wells of a 24-well plate (Costar).

The cultures were split after complete confluence (approximately every 4-6 d) and periodically monitored for infection. The relative cell composition of the cultures was monitored by cell fluorimetry using FITC-conjugated MAb that are expressed on B-CLC, including CD4, CD45R0, and CD19. Infection of surviving GI-CA-N cells was assessed by detection 
of HIV-1 p24 antigen in the culture supernatant and by detection of proviral DNA sequences by PCR as follows.

PCR analysis. HIV-1 proviral DNA was detected according to Schnittman et al. (31). Briefly, at passages 3, 5, and 7 after infection, GI-CA-N cells were washed and pelleted in PBS, lysed in $0.001 \%$ Triton X-100/0.0001\% SDS in TDE buffer (10 $\mathrm{mM}$ Tris- $\mathrm{HCl} \mathrm{pH} 8.0,0.5 \mathrm{mM}$ EDTA, $\mathrm{pH} 8$ ) with $600 \mu \mathrm{g} / \mathrm{ml}$ proteinase $\mathrm{K}$ (Boehringer Manheim, Indianapolis, IN) for $1 \mathrm{~h}$ at $56^{\circ} \mathrm{C}, 15 \mathrm{~min}$, at $95^{\circ} \mathrm{C}$. The PCR reaction mixture contained 50 $\mu l$ of DNA lysate, $50 \mathrm{pmol}$ of each primer, SK38/SK39 (gag 1551-1578; gag 1638-1665), $200 \mu \mathrm{M}$ each of four deoxynucleotide triphosphates (Boehringer Manheim), $10 \mathrm{mM}$ Tris- $\mathrm{HCl} \mathrm{pH} 8.3,2.5 \mathrm{mM} \mathrm{MgCl}_{2}, 50 \mathrm{mM} \mathrm{KCl}, 0.2 \%$ gelatin, and $2 \mathrm{U}$ of DNA polymerase from Thermus aquaticus (PerkinElmer Corp.)

Amplification was carried out with a Perkin-Elmer thermocycler 480 (denaturation $94^{\circ} \mathrm{C}$, annealing $55^{\circ} \mathrm{C}$, extension $72^{\circ} \mathrm{C}, 30$ cycles). After amplification, $30-\mu \mathrm{l}$ aliquots were mixed with ${ }^{32} \mathrm{P}$-labeled SK19 probe, denatured at $94^{\circ} \mathrm{C}$, and hybridized at $56^{\circ} \mathrm{C}$ for $15 \mathrm{~min}$. Autoradiograms of polyacrylamide gels were obtained by exposure to Kodak XAR film at $-70^{\circ} \mathrm{C}$ (see Fig. 3).

\section{RESULTS}

GI-CA-N cells adhere to all ECM tested, whereas LAN-5 cells attached to Coll I, Coll IV, and laminin but showed very weak adhesion to vitronectin and fibronectin. Both cells were capable of adhering to $t a t^{46-60}$, although not to $t a t^{65-80}$ (Fig. 1). In spite of this both cell lines were able to grow on plastic dishes precoated with either residue (Table 1).

Results related to competition experiments are reported in Figure 2, $A$ and $B$. Inhibition of cell adhesion was evaluated by comparing optical densities. Preincubation of GI-CA-N cells with soluble $t a t^{46-60}$, but not soluble $t a t^{65-80}$, inhibits the attachment of cells to a matrix of Coll I (Fig. $2 A$ ). In the same way, challenging the cells with soluble Coll I inhibits the attachment to a matrix of $\operatorname{tat}^{46-60}$ (Fig. $2 B$ ), thus suggesting the presence of a common ligand for both proteins on the surface of GI-CA-N.

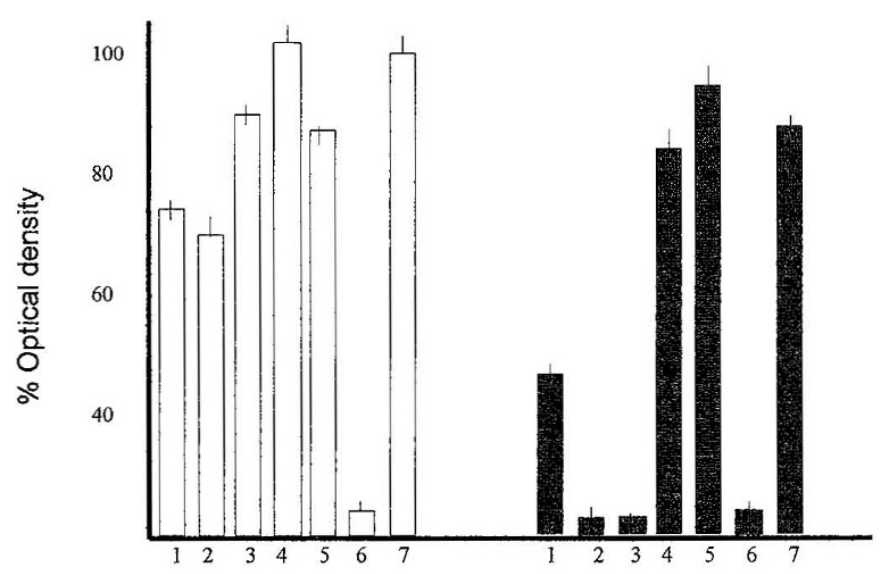

Figure 1. Adhesion of GI-CA-N ( $\square)$ and LAN-5 ( $\square$ ) cells to ECM proteins and HIV-1 tat residues. $I$, laminin; 2, Vitronectin; 3, fibronectin; 4, Coll I; 5 , Coll IV; 6 , tat $^{65-80} ; 7$, tat $^{46-60}$.
Table 1. Adhesion of $G i-C a-N$ and $L A N-5$ to ECM protein and or HIV-l tat

\begin{tabular}{lcc}
\hline Adhesion to* & GI-CA-N & LAN-5 \\
\hline BSA & $0.2-0.27$ & $0.15-1.151$ \\
Coll I & $0.7-0.56$ & $0.388-0.4$ \\
FN & $0.23-0.24$ & $0.823-0.9$ \\
tat & $0.94-0.95$ & $0.416-0.4$ \\
tat $^{46-60}$ & $0.6-0.751$ & $0.2-0.217$ \\
tat $^{65-80}$ & $0.136-0.169$ & $0.367-0.373$ \\
\hline
\end{tabular}

Cells were seeded on precoated slides, allowed to adhere for $90 \mathrm{~min}$ at $37^{\circ} \mathrm{C}$, fixed and stained, and evaluated as $A_{600}$ by microplate reader as described in Methods. Results are expressed as range obtained in three different experiments performed in duplicate. SD has been omitted being in each case $<10 \%$.

* BSA (blank); $t a t^{46-60}$ and $t a t^{65-80}$, synthetic peptides respectively from tat basic residue and RGD-containing motif.
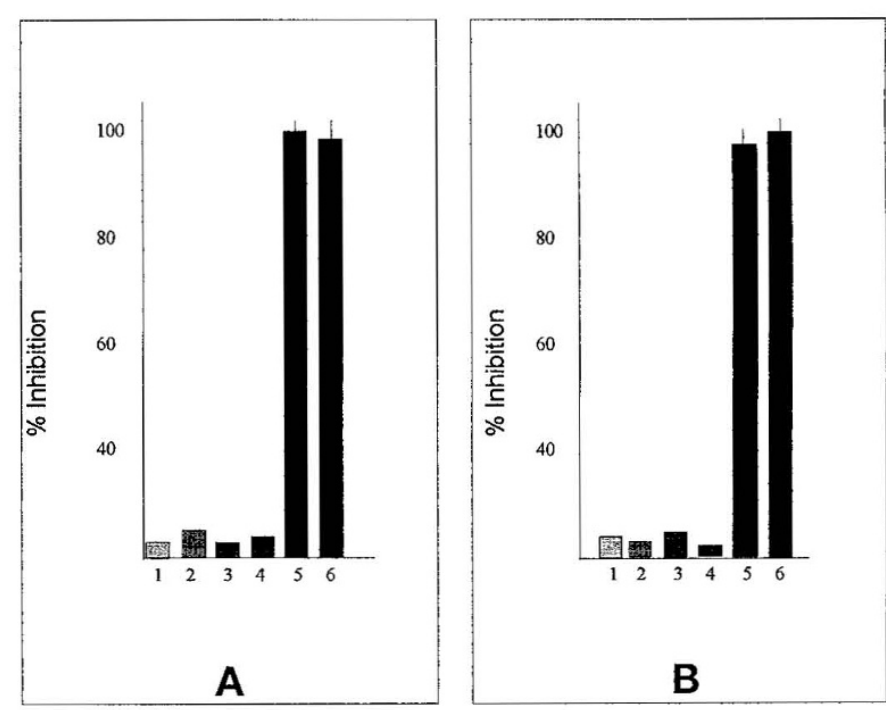

Figure 2. Inhibition of adhesion to Coll $\mathrm{I}$ and $t a t^{46-60}$ by preincubating GI-CA-N cells with $t a t^{46-60}$, Coll I and control peptides. (A) Adhesion to Coll I; $(B)$ adhesion to $t a t^{46-60}$. Gi-CA-N human neuroblastoma cells have been tested as following: $l$, preincubation with RPMI- $1640 ; 2$, preincubation with BSA; 3, preincubation with $t a t^{65-80} ; 4$, preincubation with Substance P; 5 , preincubation with Coll I; 6, preincubation with $\operatorname{tat}^{46-60}$.

GI-CA-N cells were positive for Gal-C, particularly when seeded on $t a t^{46-60}$; the expression of $200-\mathrm{kD}$ neurofilaments was induced by allowing cells to adhere on Coll I. Such an expression was not observed in cells adhering to tat ${ }^{46-60}$ (Table 2). Cell proliferation was not significantly inhibited by culturing LAN5 or GI-CA-N cells on either tat residues (not shown). When cultured on Coll I, both LAN-5 and GI-CA-N cells acquired a neuronal morphology (extension of neuritelike processes and filipodia), whereas cells adhering to $t a t^{46-60}$ were small, round, and often clustering as pseudo-rosettes.

The expression of integrin subunits by both GI-CA-N and LAN-5 cells is summarized in Table 3. As expected from the adhesion results, the pattern of the two cell lines was different. Both expressed $\beta_{1}$ when associated with different $\alpha$ isoforms.

Both GI-CA-N and LAN-5 cells were tested as negative for CD4, confirming previously published results (6). Figure 3 shows the gradual loss of HIV-1 DNA-specific sequence as detected by PCR, in GI-CA-N/B-LCL co-culture. 
Table 2. Immunocytochemical pattern of GI-CA-N and LAN-5 cells seaded on Coll-I and tat ${ }^{46-60}$

\begin{tabular}{|c|c|c|c|c|c|c|}
\hline \multirow[b]{2}{*}{$\mathrm{MAb}^{*}$} & \multicolumn{3}{|c|}{ GI-CA-N } & \multicolumn{3}{|c|}{ LAN-5 } \\
\hline & Control & Coll I & $t a t^{46-60}$ & Control & Coll I & $t a t^{46-60}$ \\
\hline GAL-C & $+\dagger$ & \pm & + & $\mathrm{Neg}$ & $\mathrm{Neg}$ & $\mathrm{Neg}$ \\
\hline HNK-1 & + & + & + & + & +++ & +++ \\
\hline GFAP & $\mathrm{Neg}$ & $\mathrm{Neg}$ & Neg & $\mathrm{Neg}$ & Neg & $\mathrm{Neg}$ \\
\hline 200-kD NF & \pm & +++ & \pm & + & $\mathrm{Neg}$ & $\mathrm{Neg}$ \\
\hline NGFr & + & $\mathrm{Neg}$ & $\mathrm{Neg}$ & \pm & $\mathrm{Neg}$ & $\mathrm{Neg}$ \\
\hline N-CAM & + & + & + & + & \pm & $\mathrm{Neg}$ \\
\hline MAG & $\mathrm{Neg}$ & $\mathrm{Neg}$ & $\mathrm{Neg}$ & $\mathrm{Neg}$ & Neg & $\mathrm{Neg}$ \\
\hline
\end{tabular}

Cells were seaded on precoated slides, allowed to adhere for $90 \mathrm{~min}$ at $37^{\circ} \mathrm{C}$, fixed, and stained with a standard procedure, as described.

* Gal-C, galactosyl-cerebroside; HNK-1, human NK-1; GFAP, glyal fibrillar acidic protein; NF, neurofilaments; NGFr, nerve growth factor receptor; N-CAM, neural cell adhesion molecule; MAG, myelin-associated glycoprotein.

$\dagger$ Fluorescence intensity: (neg) negative; $( \pm)$ equivocal; $(+)$ weakly positive; $(++)$ moderately positive; $(+++)$ strongly positive. Antibodies used and specific methods have been previously specified in detail $(8,16,17)$.

Table 3. Expression of integrin subunits by GI-CA-N and LAN-5 human neuroblastoma cells

\begin{tabular}{cccccc}
\hline & \multicolumn{2}{c}{ LAN-5 } & & \multicolumn{2}{c}{ GI-CA-N } \\
\cline { 2 - 3 } \cline { 5 - 6 } Integrin subunits & RT-PCR & IP & & RT-PCR & IP \\
\hline$\beta_{1}$ & Pos & Pos & & Pos & Pos \\
$\alpha_{1}$ & Pos & Pos & & Neg & Neg \\
$\alpha_{2}$ & Pos & Pos & & Pos & Pos \\
$\alpha_{3}$ & Pos & Pos & & Pos & Pos \\
$\alpha_{4}$ & Pos & Neg & & Pos & Pos \\
$\alpha_{5}$ & Neg & Neg & & Pos & Pos \\
$\alpha_{6 \mathrm{~A}}$ & Pos & Neg & & Pos & Pos \\
$\alpha_{6 B}$ & Pos & Neg & Pos & Pos \\
$\alpha_{v}$ & Pos & Pos & Pos & Pos \\
$\beta_{3}$ & Pos & Pos & Pos & ND \\
$\beta_{4}$ & Pos & Neg & Neg & Neg \\
$\beta_{5}$ & Neg & ND & Pos & ND \\
$\beta_{6}$ & Neg & Neg & Neg & Neg \\
\hline
\end{tabular}

IP, immunoprecipitation; ND, not done (see Ref. 12 for details).

\section{DISCUSSION}

The absence of $\alpha 4$ and $\alpha 5$ subunits in LAN- 5 cells explain the weaker adhesion to fibronectin, compared with GI-CA-N which express these isoforms. Because both cell lines firmly adhere to $t a t^{46-60}$, although not to $t a t^{65-80}$, the integrin receptors involved in fibronectin recognition which include $\alpha 4$ and $\alpha 5$ subunits should not be involved. Adhesion to $t a t^{46-60}$ is inhibited by preincubating cells with Coll I (Fig. 2), although not with fibronectin nor with laminin (not shown). In addition, preincubation of cells with $t a t^{46-60}$ inhibit attachment to the same fragment and to Coll I (Fig. 2), although not to the other ECM (not shown). Preincubation with VIP, substance P, and tat ${ }^{65-80}$ did not inhibit adhesion to $t^{4 t^{46-60}}$ nor to Coll I. This is partially in contrast with Barillari's report (24). By testing spindle-shaped vascular endothelial cells, these authors demonstrated that the adhesion to HIV-1 tat is associated with the amino acid sequence RGD through a specific interaction with the integrin receptors $\alpha_{5} \beta_{1}$ and $\alpha_{v} \beta_{3}$, although it is augmented by the basic region. In the neural cell model herein described, the implication of $\alpha_{5}$ and RGD domain cannot be excluded for GI-CA-N, although it is excluded for LAN-5 (Table 3; Fig. 1). Thus, the role of the basic residue appears to be more than just accessory. It is then possible that human neural cells adhere to tat with receptors other than that identified for endothelial cells (24).

\section{GI-CA-N}

GI-CA-N INF $3^{\circ}$

GI-CA-N INF $5^{\circ}$

GI-CA-N INF $7^{\circ}$

\section{LB}

A301

ACH-2 103

ACH-2 102

ACH-2 10

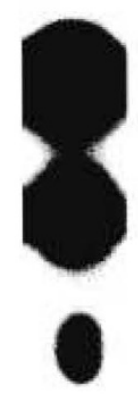

ACH-2 1

Figure 3. PCR amplification of HIV-1 DNA in uninfected and in infected GI-CA-N cells at pasages 3,5, and 7 after infection. DNA amplification was obtained by using gag-specific primers as described in Methods. Intensities of PCR signal in $6 \times 10^{4}$ cells are compared with 10 -fold serial dilutions of cell lysates from $\mathrm{ACH}-2$ (positive control). $L B$, lysis buffer (negative control); $A 301$, cells (uninfected negative control).

By infecting NB cells with HIV-1 we ascertained the lack of permissivity of GI-CA-N (CD4,- Gal- $\left.^{+}\right)$to the infection. Thus, GI-CA-N cells may possibly allow HIV-1 entry through Gal-C, although not permissive to HIV-1 replication. We do not know yet if infected cells may eventually transduce and secrete tat; experiments to determine this are presently being run in our laboratory. However, it is clear now that neural cells not permissive to HIV-1 infection may adhere to a tat residue which compete with Coll I. The effect of a three-dimensional Coll I preparation on the structural organization of GI-CA-N 
cells has been recently observed in our laboratory (G. Alessandri, unpublished results). In this model, Coll I induces GI-CA-N cell growth arrest and neuronal differentiation. A similar phenomenon has been recently observed by BergsteinsDottir et al. (10) in a different neural cell model. Thus, it is likely that adhesion to tat may perturb the neuronal differentiation processes, including the inhibition of $200-\mathrm{kD}$ NF expression (Table 2), by a mechanism probably based on Coll I receptor competition.

According to Ensoli et al. (33) HIV-1 tat is secreted by infected cells and possibly degraded by membrane and extracellular proteases to smaller fragments. By showing here that some of the tat fragments interact with ECM receptors, we confirm that a etiopathogenetic mechanism of neural cell function disruption may be based on such a phenomenon. Results presented by Cupp et al. (22) would confirm this hypothesis. These authors demonstrated the ability of the HIV-1 tat protein to increase expression of TGF- $\beta^{1}$, a cytokine with potent immunosuppressive activity, in human astrocytic glial cells. Thus, implications of the tat-mediated induction of TGF- $\beta 1$ expression and cytokine involvement in the regulation of immune response and CNS pathology is very likely.

In previous reports we demonstrated that $\gamma$-IFN and TNF- $\alpha$, both of which are actively secreted by HIV-1-infected cells, modulate human neural cell proliferation and differentiation $(13,23,24)$, modifying integrin expression (12). Thus, tat, by altering a complex combination of cytokine regulation and adhesion processes, may affect neuron and accessory cell maturational processes. The involvement of tat in altering the expression of cellular regulatory factors, including ECM receptors which, in turn, may mediate the altered physiology of the cells would result in dysmyelination and gliosis. Other HIV-1 proteins may also be involved. Recent results in the study in vivo of a mice transgenic model support the evidence that gp120 also plays a key part in HIV-1-associated nervous system impairment (32). Thus, the interaction of gp120 and tat in determining the observed neurotoxicity in the developing nervous system is very likely.

\section{REFERENCES}

1. Shaw GM, Harper ME, Epstein LG, Gadjusek DC, Rue RW, Navia BA, Petito CK, O'Hara CJ, Cropman JE, Cho E, Oleske JM, Wong-Staal F, Gallo RC 1985 HTLV-III infection in brains of children and adults with AIDS encephalopathy. Science 227:177-181

2. M Mintz 1994 Clinical comparison of adult and pediatric NeuroAIDS. Adv Neuroimmunol 4:207-221

3. Dickson DW, Lenna JF, Nelson SJ, Weidenheim KM 1993 Central nervous system pathology in pediatric AIDS. Ann NY Acad Sci 693:90-105

4. Pizzo PA, Eddy J, Ballon J, Balis F, Murphy RF, Moss H, Walters P, Browers P, Jaransky P, Rubin M 1988 Effect of continuous intravenous infusion of zidovudine (AZT) in children with symptomatic HIV infection. N Engl J Med 319:889-886

5. Brouwers P, Heyes MP, Moss HA, Wolters PL, Poplack DG, Markey SP, Pizzo PA 1993 Quinolinic acid in the cerebrospinal fluid of children with symptomatic human immunodeficiency virus type- 1 disease-relationships to clinical status and therapeutic response. J Infect Dis 168:1380-1386

6. P Brouwers, C Decarli, G Tudorwilliams, L Civitello, H Moss, P Pizzo 1994 Interrelations among patterns of change in neurocognitive, CT brain imaging and CD4 measures associated with anti-retroviral therapy in children with symptomatic HIV infection. Adv Neuroimmunol 4:223-231

7. Oberfield SE, Cowan L, Levine LS, George AE, David R, Litt A, Rojas V, Kairam R 1994 Altered cortisol response and hippocampal atrophy in pediatric HIV disease. J AIDS 7:57-62

8. Cara A, Pecorara M, Cornaglia-Ferraris P 1992 Analysis of CD4 gene expression in human fetal brain and neuroblasts. Cell Mol Neurobiol 12:131-142
7. Yamada KM, Aota S, Akiyama SK, Laflamme SE 1992 Mechanisms of fibronectin and integrin function during cell adhesion and migration. Cold Spring Harbor Symp Quant Biol 57:203-212

8. Edelman GM 1992 Mediation and inhibition of cell adhesion by morphoregulatory molecules. Cold Spring Harbor Symp Quant Biol 57:317-325

9. Valentini RF, Vargo TG, Gardella JA, Aebischer P 1993 Patterned neuronal attachment and outgrowth on surface modified, electrically charged fluoropolymer substrates. J Biomater Sci-Polym Ed 5:13-36

10. Bergsteins-Dottir K, Hashimoto Y, Brennan A, Mirsky R, Jessen KR 1993 The effect of 3-dimensional collagen type-I preparation on the structural organization of guinea pig enteric ganglia in culture. Exp Cell Res 209:64-75

11. Payne HR, Lemmon V 1993 Glial cells of the O-2A lineage bind preferentially to N-cadherin and develop distinct morphologies. Dev Biol 159:595-607

12. Seki T, Arai Y 1993 Distribution and possible roles of the highly polysialylated neural cell adhesion molecule (NCAM-H) in the developing and adult central nervous system. Neurosci Res 17:265-290

13. Harper SJ, Walsh FS, Doherty P 1993 Neurite outgrowth of spinal neurons on tissue sections of embryonic muscle is largely integrin-dependent. Neurosci Lett 159:202-206

14. Erickson CA, Perris R 1993 The role of cell-cell and cell matrix interactions in the morphogenesis of the neural crest. Dev Biol 159:60-74

15. Rozzo C, Ratti P, Ponzoni M, Cornaglia-Ferraris P 1993 Modulation of $\alpha 1 \beta 1, \alpha 2 \beta 1$ and $\alpha 3 \beta 1$ integrin heterodymers during human neuroblastoma cell differentiation. FEBS Lett 332:263-267.

16. Ponzoni M, Guarnaccia F, Corrias MV, Cornaglia-Ferraris P 1993 Uncoordinate induction and differential regulation of HLA Class-I and Class-II expression by $\gamma$-Interferon in differentiating human neuroblastoma cells. Int J Cancer 55:817-823

17. Cornaglia-Ferraris P, Bocca P, Cara A, Carbone R, Conti A, Corrias Mv, Guamaccia F, Lanciotti M, Lucarelli E, Montaldo PG, Ratti P, Rozzo C, Ponzoni M 1993 Human neuroblastoma: new therapeutic strategies suggested by experimental models. Clin Chem Enzyme Commun 5:327-337

18. Zauli G, Gibellini D, Milani D, Mazzoni M, Borgatti P, La Placa M, Capitani S 1993 Human immunodeficiency virus type- 1 tat protein protects lymphoid, epithelial, and neuronal cell lines from death by apoptosis. Cancer Res 53:4481-4485

19. Milani D, Zauli G, Neri LM, Marchisio M, Previati M, Capitani S 1993 Influence of the human immunodeficiency virus type-1 TAT protein on the proliferation and differentiation of PC12 rat pheochromocytoma cells J. Gen Virol 74:2587-2594

20. Jeang KT, Chun R, Lin NH, Gatignol A, Glabe CG, Fan H 1993 In vitro and in vivo binding of human immunodeficiency virus type-1 tat protein and Sp1 transcription factor. J Virol 67:6224-6233

21. Leguern M, Shioda T, Levy JA, Chengmayer C 1993 Single amino acid change in tat determines the different rates of replication of 2 sequential HIV-1 isolates. Virology 195:441-447

22. Cupp C, Taylor JP, Khalili KL, Amini S 1993 Evidence for stimulation of the transforming growth factor- $\beta-1$ promoter by HIV- 1 tat in cells derived from CNS. Oncogene 8:2231-2236

23. Kolson DL, Buchhalter J, Collman J, Hellmig B, Farrell CF, Debouck C, GonzalezScarano F 1993 HIV-1 tat alters normal organization of neurons and astrocytes in primary rodent brain cell cultures-RGD sequence dependence. AIDS Res Hum Retroviruses 9:677-685

24. Barillari G, Gendelman R, Gallo RC, Ensoli B 1993 The tat protein of human immunodeficiency virus type-1, a growth factor for AIDS Kaposi sarcoma and cytokine-activated vascular cells, induces adhesion of the same cell types by using integrin receptors recognizing the RGD amino acid sequence. Proc Natl Acad Sci USA 90:7941-7945

25. Toggas SM, Masliah E, Rockenstein EM, Rall GF, Abraham CR, Mucke L 1994 Central nervous system damage produced by expression of the HIV-1 coat protein gp120 in transgenic mice. Nature 367:188-193

26. Longo L, Christiansen H, Christiansen N, Cornaglia-Ferraris P, Lampert F 1988 $\mathrm{N}-m y c$ amplification at chromosome band $1 \mathrm{p} 32$ in neuroblastoma cells as investigated by in situ hybridization. J Cancer Res Clin Oncol 114:636-640

27. Cornaglia-Ferraris P, Ponzoni M, Melodia A, Mariottini GL, Donti E, Di Martino D, Tonini GP 1990 A new human highly tumorigenic neuroblastoma cell line with undetectable expression of N-myc. Pediatr Res 27:1-6

28. Ponzoni M, Cornaglia-Ferraris P 1993 Interferon- $\gamma$-stimulated and GTP-bindingproteins-mediated phospholipase-A(2) activation in human neuroblasts. Biochem $\mathrm{J}$ 294:893-898

29. Ponzoni M, Lucarelli E, Corrias MV, Cornaglia-Ferraris P 1993 Protein kinase C isoenzymes in human neuroblasts. Involvement of $\mathrm{PKC} \varepsilon$ in cell differentiation. FEBS Lett 322:120-124

30. De Maria A, Pantaleo G, Schnittman SM, Grenhouse JJ, Basele M, Orenstain JM, Fauci AS 1991 Infection of CD8 ${ }^{22}$ T-lymphocytes with human immunodeficiency virus: requirement for interaction with infected $\mathrm{CD}^{+}$cells and incuction of infectious virus from chronically infected $\mathrm{CD}^{+}$cells J Immunol 146, 2220-2228

31. Schnittman SM, Psallidopulos MC, Lane HC, Thompson L, Baseler M, Massari F, Fox CH, Salzman NP, Fauci AS 1990 The reservoir for HIV-1 in human peripheral blood is a T cell that maintains expression of CD4. Science 245:305-3008

32. Toggas M, Masliah E, Rockenstein EM, Rall GF, Abraham CR, Mucke C 1993 Central nervous system damage produced by expression of the HIV-1 coat protein gp 120 in transgenic mice. Nature 367:188-193

33. Ensoli B, Gendelman R, Markam P, Fiorelli F, Colombini S, Raffeld M, Cafaro A, Chang HK, Brady JN, Gallo RC 1994 Synergy between bfgf and HIV-1 tat protein in induction of Kaposi's sarcoma. Nature 371:674-680 